\title{
EDUCACIÓN SOCIAL, ARTE URBANO, GRAFFITI Y ACTIVISMO FEMINISTA
}

\section{Social education, urban art, graffiti and feminist activism.}

\author{
TATIANA PÉREZ SANTOS \\ GRADUADA EN EDUCACIÓN SOCIAL \\ ESPECIALISTA UNIVERSITARIA EN ESTUDIOS DE GÉNERO Y GESTIÓN DE POLÍTICAS DE \\ IGUALDAD \\ tatiana_psa@hotmail.com \\ Recibido: 14/03/2018 /Aceptado: 16/04/2018 \\ Cómo citar: Pérez Santos, Tatiana (2018). Educación social, arte urbano, graffiti y activismo feminista. \\ Tabanque, 31. p. 164-184 \\ DOI: https://doi.org/10.24197/trp.31.2018.164-184
}

Resumen: Durante este artículo, nos adentraremos en reflexionar sobre la capacidad reivindicativa del arte, concretamente el urbano, sirviendo como un elemento catalizador de procesos sociales y comunitarios. Además, estableceremos puntos de unión con la labor del Educador/a Social y el artivismo o activismo desde el arte y de qué manera todo ello puede ayudar a la reivindicación feminista. Para ello, ahondaremos de manera breve, en la obra de diferentes mujeres artistas urbanas, naturales de distintos países y poder establecer así un mapa que abarque diferentes latitudes y maneras de intervenir en el espacio urbano.

Finalmente, comentaremos de manera breve una intervención llevada a cabo en un aula de mayores y demostrar así las posibilidades comentadas con anterioridad sobre arte urbano para la intervención social y el desarrollo cultural comunitario.

Palabras clave: Arte urbano; graffiti; Educación Social; feminismo; intervención social.

Abstract: During this article, we will enter into the reflexive capacity of art, specifically urban art, serving as a catalyst for social and community processes. In addition, we will establish points of union with the work of the Social Educator and the artivism or activism from the art and how all this can help the feminist claim. To do this, we will briefly delve into the work of different women urban artists, natives of different countries and thus establish a map that covers different latitudes and ways of intervening in the urban space.

Finally, we will comment briefly one intervention, carried out in an adult classroom and thus demonstrate the previously discussed possibilities of urban art for social intervention.

Keywords: Urban art; graffiti; Social Education; feminist; social intervention.

Sumario: La expresión artística en la calle; 2. Una intervención con mujeres a partir del arte urbano; 3. Conclusiones; 4. Bibliografía 


\section{LA EXPRESIÓN ARTÍSTICA EN LA CALLE \\ 1.1. El arte urbano}

El arte urbano, también denominado callejero, proviene de la expresión inglesa street art. Este arte contestatario señala a todo aquel arte que se realiza en la calle y que tiene la característica de ilegal.

Nicholas Ganz (2006) plantea una diferenciación entre el arte urbano y el graffiti: mientras que este último se caracteriza por que los y las artistas sientan el deseo de difundir su individualidad mediante su tag - firma -, en el primero se establece todo un abanico de técnicas y procesos más elaborados.

En este sentido, podemos comenzar a hablar de arte urbano a partir de los años 90, cuando se instala el denominado postgraffiti y con él una gran gama de técnicas artísticamente mucho más avanzadas: jardinería de guerrilla, pegatinas, stencil, adbusting, mosaicos, plantillas, etc. (Pérez, 2017).

Inherente al arte urbano encontramos el graffiti, en el cual están sus orígenes. Este arte continúa en constante desarrollo y evolución tanto en técnicas como en estilos. La técnica más comúnmente utilizada tal vez sea el stencil o estarcido consistente en realizar una plantilla previa que después estampamos en el muro. Esta técnica es la utilizada por el famoso stencilero Banksy. El estarcido es una manera de intervenir muy utilizada pues tiene la ventaja de permitir al artista una intervención en el espacio público rápida y limpia, dos características muy valoradas dentro del arte urbano.

\subsection{Los graffiti}

Como he señalado anteriormente, el graffiti es una de las vertientes más conocidas del arte urbano pero no la única. El muro o la fachada, se convierte en un lienzo ideal para que los y las artistas plasmen sus inquietudes y reivindicaciones, colocándolas así en el espacio público a la vista de cualquier transeúnte y sin necesidad de entrar en las galerías de arte.

Este arte contestatario y reivindicativo puede ser más o menos elaborado pero mantiene a lo largo del tiempo unas características constantes en relación al estilo, la intencionalidad y la ubicación (Ganz, 2006).

\section{a. Antecedentes y primeros graffitis}

Si recorremos las calles de nuestra ciudad o de cualquier otra, enseguida nos llamará la atención la gran cantidad de pintadas que encontramos en las fachadas, muros y paredes. Todos ellos, más o menos artísticos, dejan constancia del paso de 
las personas por las ciudades y de cómo las han habitado, la manifestación más evidente de la voz del pueblo.

El término graffiti, proviene del italiano graffiare, garabatear, remitiéndonos a la escritura mural. Podemos acudir también al griego: grapho, grabar o escribir.

Si establecemos que todos aquellos graffitis son la voz del pueblo, podemos remontarnos a las pinturas rupestres encontradas en las cuevas prehistóricas para hallar los primeros antecedentes. A pesar de ello, a estas pinturas las denominaremos pinturas murales y no graffitis a falta de palabra escrita.

Escribir o rayar el muro ha sido un impulso constante en todas las sociedades estudiadas pues sirvió y sigue sirviendo para dejar testimonio y constancia de los aspectos cotidianos de las personas que habitan las ciudades. En la antigüedad, son especialmente conocidos los grafitos encontrados en Pompeya que, al ser cubierta de ceniza por el volcán Vesubio en el año 79 d.C, ha permitido conservar piezas cotidianas casi en perfecto estado. De esta manera, encontramos cómo los romanos escribían en las paredes de las letrinalias, letrinas de la antigua Roma, diferentes mensajes: políticos, amorosos, servicios de prostitución o burlas a otras personas. Sin duda, todo esto nos remite a cualquier servicio público de hoy en día.

Este abanico de graffitis encontrados, nos ofrecen testimonios de gran valor sobre la realidad social y cultural de sociedades anteriores que ni el teatro ni la literatura heredada nos ha permitido conocer. Hemos podido conocer el día a día de las personas anónimas, sin pretensiones estéticas, tan solo por el impulso de dejar constancia de haber habitado esos lugares. Esta misma idea se desprende de los graffitis de los y las artistas del Nueva York de los años 60.

En otra línea, podemos encontrar otros antecedentes al arte urbano y al graffiti. Para ello debemos remontarnos al siglo XX en el muralismo mexicano, impulsado este por el propio poder político. Con Diego Rivera como principal referencia, los muros de la ciudad se convirtieron en lienzos donde criticar la situación sociopolítica del país.

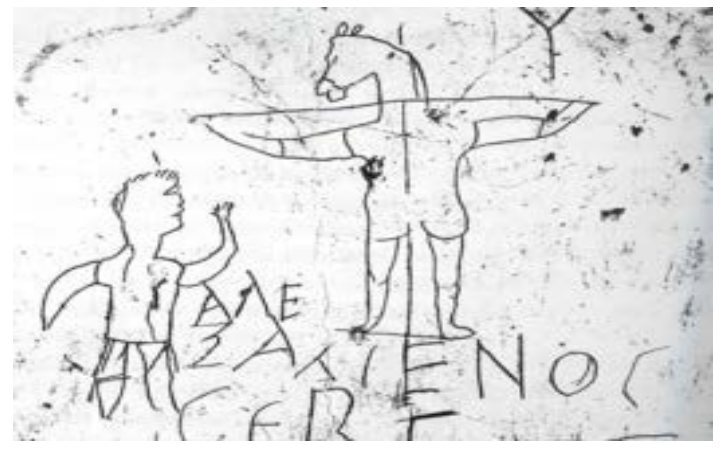


Imagen 1. Grafitos encontrados en Pompeya.

\section{b. Aparición del graffiti hip hop}

Entramos de lleno ya en conocer el contexto sociocultural que rodeó a los primeros escritores de graffiti. Jesús de Diego explica que el graffiti ha sido la representación artística más juzgada y condenada por el hecho de atentar contra la propiedad privada (De Diego, 2000).

En otro lugar, señalo que yendo un paso más allá, podríamos añadir que el rechazo al graffiti por parte de la Historia del Arte "oficial” puede ser el reflejo de una sociedad capitalista que evita y rechaza la pobreza y por tanto también a este arte contestatario que surgió de los barrios más pobres de Estados Unidos y que durante muchos años se vinculó a jóvenes de extrarradio y conflictivos (Pérez, 2017).

Cuando hablamos de los primeros escritores ${ }^{1}$ de graffiti, debemos saber que responde a un perfil concreto: hombres, residentes en guetos de la ciudad y en zonas empobrecidas, principalmente en los barrios de Brooklyn y Bronx. De esta realidad nacen los primeros antecedentes de lo que hoy conocemos como graffiti y arte urbano.

Partiendo de esta base y conociendo cómo se desarrollaron los inicios de este arte contestatario surgido de los barrios más empobrecidos de Nueva York, debemos ir un paso más allá y preguntarnos dónde se encontraban las mujeres; ¿las mujeres también rayan el muro?, ¿cuáles son sus reivindicaciones?, ¿podemos entresacar de ellas una lectura de género, que sirva como herramienta para el feminismo?

\subsection{Activismo feminista desde el arte urbano}

Para encontrar la formulación más clara de la teoría feminista, debemos remontarnos a la Ilustración donde se da lugar al conjunto de reivindicaciones de igualdad por parte de las mujeres y que todavía hoy están por cumplirse.

En todo el mundo y en diferentes etapas históricas, desde el feminismo se han articulado actividades y movimientos que llevaban al planteamiento encabezado por Kate Millet (1970) de que lo personal es político y por tanto los problemas

\footnotetext{
${ }^{1}$ Escritor/a: palabra con la que se definían los primeros graffiteros neoyorquinos, mayoritariamente hombres.
} 
tradicionalmente considerados "de mujeres" salen del espacio privado de lo doméstico y se sitúan en el centro del debate sociopolítico.

A lo largo de la historia, podemos acudir a diferentes facetas y veremos cómo los hombres se han apoderado de la esfera pública y de poder que ha sido gobernado por ellos y para ellos. La historia de las imágenes por tanto, no se ha salvado de construirse desde una visión parcial que deja de lado a la mitad de la humanidad. Si hacemos un recorrido rápido tratando de encontrar la aportación de las mujeres al arte, tal vez serán pocas las obras que encontramos. Esto sin duda nos remite a la pregunta planteada por Linda Nochlin en 1971: “¿por qué no han existido grandes mujeres artistas?”. Esta era una pregunta incomoda pues venía a cuestionar toda la historia que se nos había mostrado como única e incuestionable.

De esta manera llegamos hasta hoy en día y nos planteamos ¿las mujeres pintan graffiti? Y la respuesta es afirmativa como veremos más adelante. Las mujeres, contra todo pronóstico han entrado también en este mundo del arte urbano masculinizado y lo han hecho estableciendo sus propias producciones.

Griselda Pollock (2013), señalaba que llevar a cabo una historia del arte femenina y feminista, no se debía limitar exclusivamente a añadir nombres de mujeres a la lista de hombres. Debe suponer también una relectura de reivindicación y conciencia feminista. Se debe de dar como un arte que se desarrolle y se piense desde la mirada femenina (Pérez, 2017).

Señala Ana de Blas (2018), que el artivismo, o activismo desde el arte, está inundando los muros de las ciudades y los barrios como ya ocurriría en los años setenta y particularmente el arte urbano activista y feminista quiere formar parte de este momento histórico de reivindicación. Destaca además que todas estas imágenes formarán parte de los nuevos clásicos de la cultura popular. A pesar de toda esta explosión creativa, a las mujeres las sigue costando entrar en mundos masculinizados y deben de esforzarse y demostrar el doble para poder llegar a ser juzgadas bajo los mismos cánones que los hombres.

Es igualmente importante, que nos detengamos brevemente en destacar la peligrosa trivialización del feminismo como "moda" y a la que muchas personas se unen. Sin ir más lejos, toda imagen de alguna mujer histórica como pueden ser Virginia Woolf o Frida Kahlo, tan utilizada como reclamo de publicidad, pueden ser objeto de convertirse en productos que rentabilizar y comercializar. Además hemos visto cómo diferentes marcas han sacado su camiseta donde, parecen querer incitar a las chicas a unirse al feminismo por ser la nueva tendencia que ahora se "lleva". De nuevo, Ana de Blas nos advierte sobre ello y nos remite a la famosa foto de Angela Davis de los setenta y su uso comercial (De Blas, 2018). 

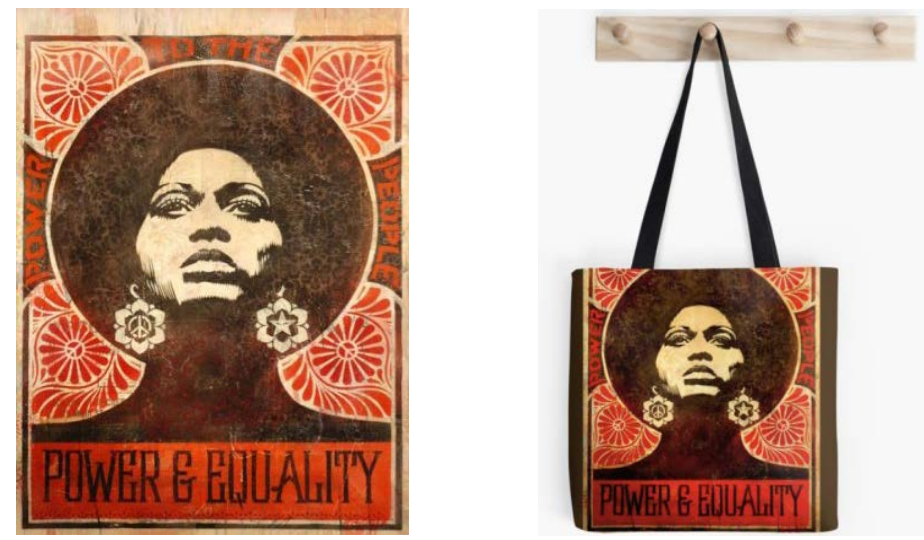

Imagen 2. Publicidad comercial con la imagen de Ángela Davis.

\subsection{Arte urbano y graffiti como recurso para el feminismo y la educación social}

De un tiempo a esta parte, hemos visto cómo el arte urbano se ha constituido como un importante movimiento creativo para el desarrollo de diferentes procesos culturales y comunitarios. Ejemplos de ello los encontramos en diferentes festivales de arte urbano que se llevan a cabo en España como el Barrio del Oeste en Salamanca, MIAU (Museo Inacabado de Arte Urbano) en Fanzara, Castellón, Bloop Festival en Ibiza o Madrid Street Art Projet en la capital.

Además, en diferentes partes del mundo también encontramos ejemplos: Nueva Zelanda, Inglaterra, Croacia o Canadá. En todos estos lugares, vemos cómo cada vez más mujeres plasman sus reivindicaciones en los muros y con ello su particular manera de ver el mundo.

Como plantea Ascensión Moreno en su libro La mediación artística (2016), las artes se evidencian como una nueva forma de dar respuestas a las necesidades sociales porque plantean el acceso a la cultura, la ruptura de la mirada estereotipada, el desarrollo de la resiliencia y el empoderamiento.

De todo lo anterior, se valen las mujeres para tomar el espacio público y colocar todas sus reivindicaciones a la vista de todos los espectadores, para interpelarles de manera directa planteando cuestionamientos a las normas heteropatriarcales existentes.

Por todo ello, el arte urbano puede ser una herramienta ideal para continuar con las reivindicaciones del feminismo y además, puede ser también un compañero de camino perfecto para la Educación Social y permitir intervenir en diferentes 
colectivos y sectores de la población utilizando el arte como un mediador, constituyéndose así como una herramienta de intervención favoreciendo mejores relaciones sociales, de grupo y comunitarias (Moreno, 2016).

\subsection{Algunas autoras que han marcado tendencia}

Como hemos venido comentando, mujeres artistas de todo el mundo, se están sumando al arte urbano y al graffiti para construir las ciudades también desde su punto de vista y colocar en el espacio público sus reivindicaciones.

El arte urbano y el activismo, como he venido sosteniendo, puede ser un aliado perfecto para las reivindicaciones feministas. Al realizarse en la calle, el arte urbano sitúa en el espacio público y a la vista de cualquier, persona todo aquello que queramos plasmar sobre el muro.

Gracias a una investigación anterior, puedo sostener que las mujeres están siendo pioneras en cuanto a técnicas se refiere a la hora de llevar a cabo intervenciones urbanas y además lo están haciendo desde una perspectiva de género (Pérez, 2017). Especial atención merecen también las dimensiones con las que normalmente trabajan la mayoría de las artistas, nada habituales para las mujeres en otros momentos de la historia. Además, estamos hablando de un arte no elitista, que se lleva a cabo en el espacio urbano y de manera pública a la cual, cualquier persona puede acceder, independientemente de sus posibilidades económicas para pagar la entrada a un museo.

Para ello, a continuación hablaremos sobre diferentes mujeres artistas y ahondaremos en su producción artística para conocer qué derechos civiles, sexuales o reproductivos reclaman. Dependiendo en qué zona geográfica se lleven a cabo los graffitis y las intervenciones urbanas, veremos cómo varían también las reivindicaciones: violencia policial, derecho al aborto, feminicidios, violencia de género, brecha salarial, techo de cristal, etc (Pérez, 2017).

De esta manera, en Estados Unidos y Europa parece que las mujeres hemos conquistado todos los derechos para ser iguales que los hombres, pero sabemos que no es así. Basta con conocer la brecha salarial que existe en diferentes países europeos, atrasos en políticas sociales y de igualdad, etc. Que en países considerados democráticos sigan rigiéndose por desigualdades de este tipo, conlleva que diferentes artivistas tomen los muros.

Este es el caso por ejemplo de Swoon (Caledonia Dance Curry), artista natural de Estados Unidos que utiliza técnicas mixtas de gran formato para sus 
obras. Con sus figuras realistas y creadas a partir de papel reciclado, acude a fuentes populares para llevar a cabo sus obras y sus mensajes. Para Swoon, es importante que las mujeres recuperen las ciudades para sí mismas y se adueñen de los espacios públicos, los cuales deben poder transitar sin miedo, como así lo refleja en su obra NeeNee.

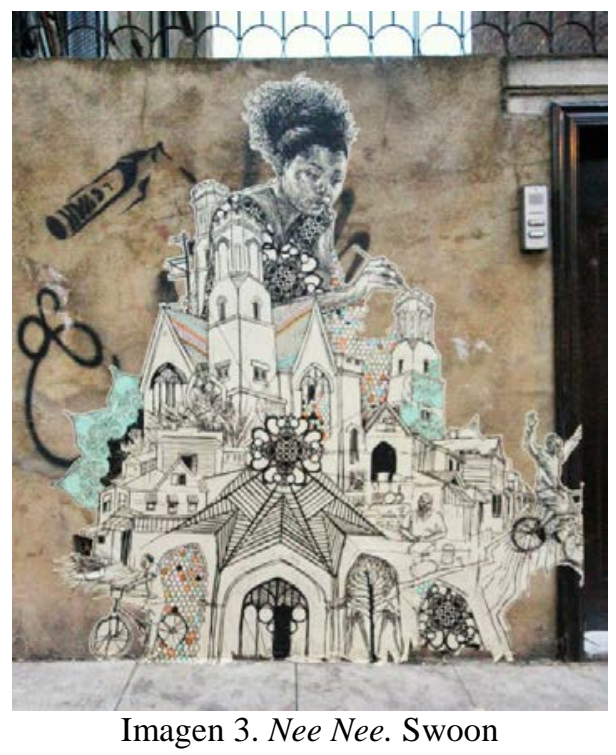

Mención merece también el grupo Lata 65. Este grupo lo conforman mujeres mayores de 65 años que están revolucionando las calles de Portugal con sus graffitis. Apoyadas por diferentes artistas, gracias a este proyecto, las mujeres que forman parte de él se están familiarizando con el arte urbano además de apostar por un envejecimiento activo y saludable.

Este grupo, se caracteriza por el uso de stencil para llevar a cabo su obra y ofrece la posibilidad de ampliar los límites del arte urbano y el graffiti, históricamente ligado a la juventud y marginalidad. Se basa principalmente en plasmar el tag, la firma de cada artista sobre la pared. 


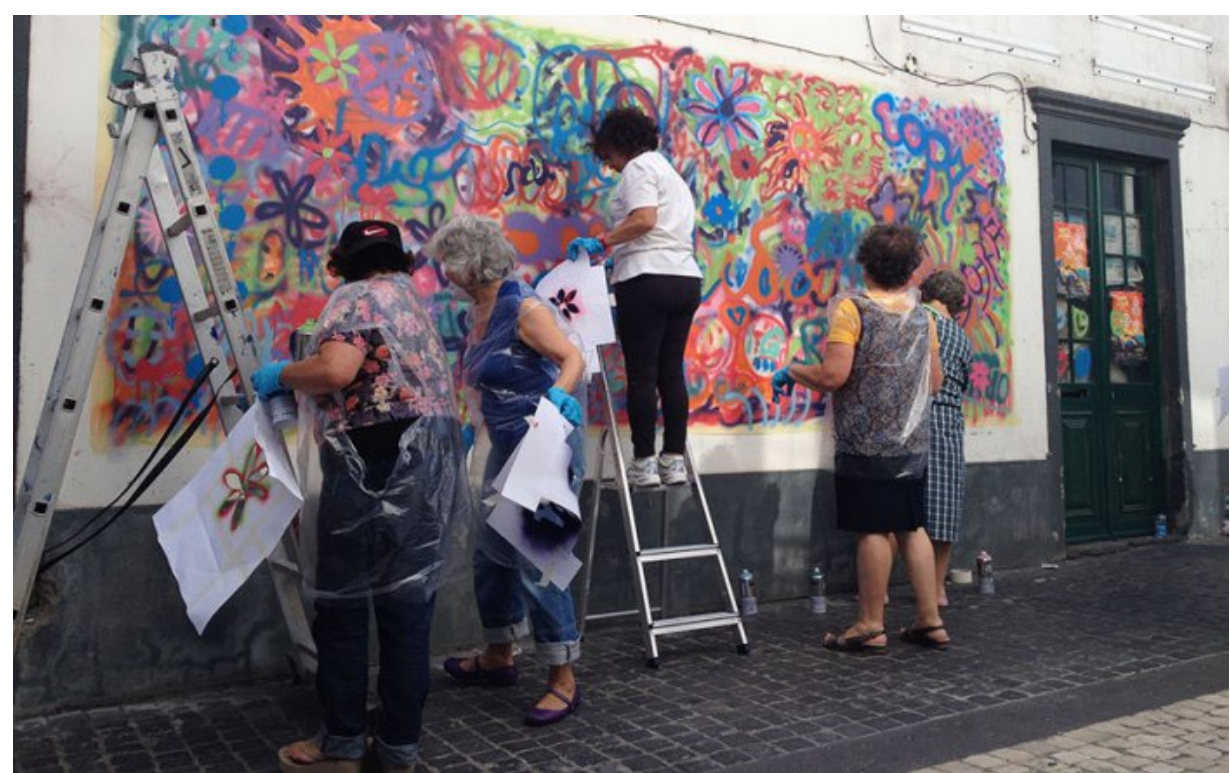

Imagen 4. Mural Lata65. Técnica: stencil.

En otro sentido, encontramos a la artista valenciana Raquel Rodrigo, que trabaja bajo el pseudónimo de Arquicostura. La innovación fundamental es que Arquicostura trabaja el bordado en grandes rejillas, que posteriormente pega a la pared y no con el bote de espray. Para llevar a cabo sus instalaciones, utiliza el píxel como unidad mínima de creación y a partir de ahí construye su obra.

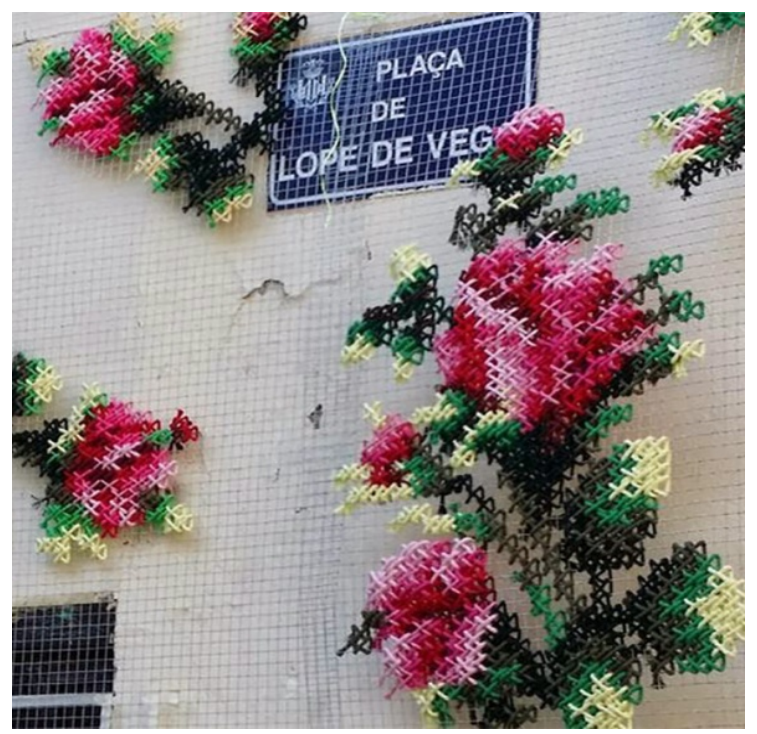

Imagen 5. Arquicostura. S/T 
Arquicostura reivindica y recupera el ganchillo y el bordado, consideradas artes menores por ser artes llevadas a cabo por mujeres, y las dota de valor y de significado. Trabaja con los elementos que ya existen, añade sus creaciones y nos ofrece otra mirada de la ciudad. Suele intervenir en lugares abandonados o muy deteriorados.

Siguiendo en la línea de Arquicostura, nos centramos ahora en el arte urbano de América Latina.

Comentaba al principio de este artículo que en esta región, particularmente en México, es interesante hablar sobre muralismo por la amplia tradición que subyace, particularmente durante el siglo XX.

Nacer mujer en lugares donde existen altos niveles de desigualdad y exclusión social, supone un gran avance llevar a cabo estrategias de empoderamiento femenino.

Encontramos así a la artista brasileña Karen Bazzeo, bajo el pseudónimo Dolorez Crochez. Al igual que la artista anterior, Bazzeo utiliza las telas como herramienta para la intervención y la reivindicación, concretamente el ganchillo. Sus técnicas son absolutamente novedosas y enlazan con la tradición textil vinculada tradicionalmente con las mujeres. 


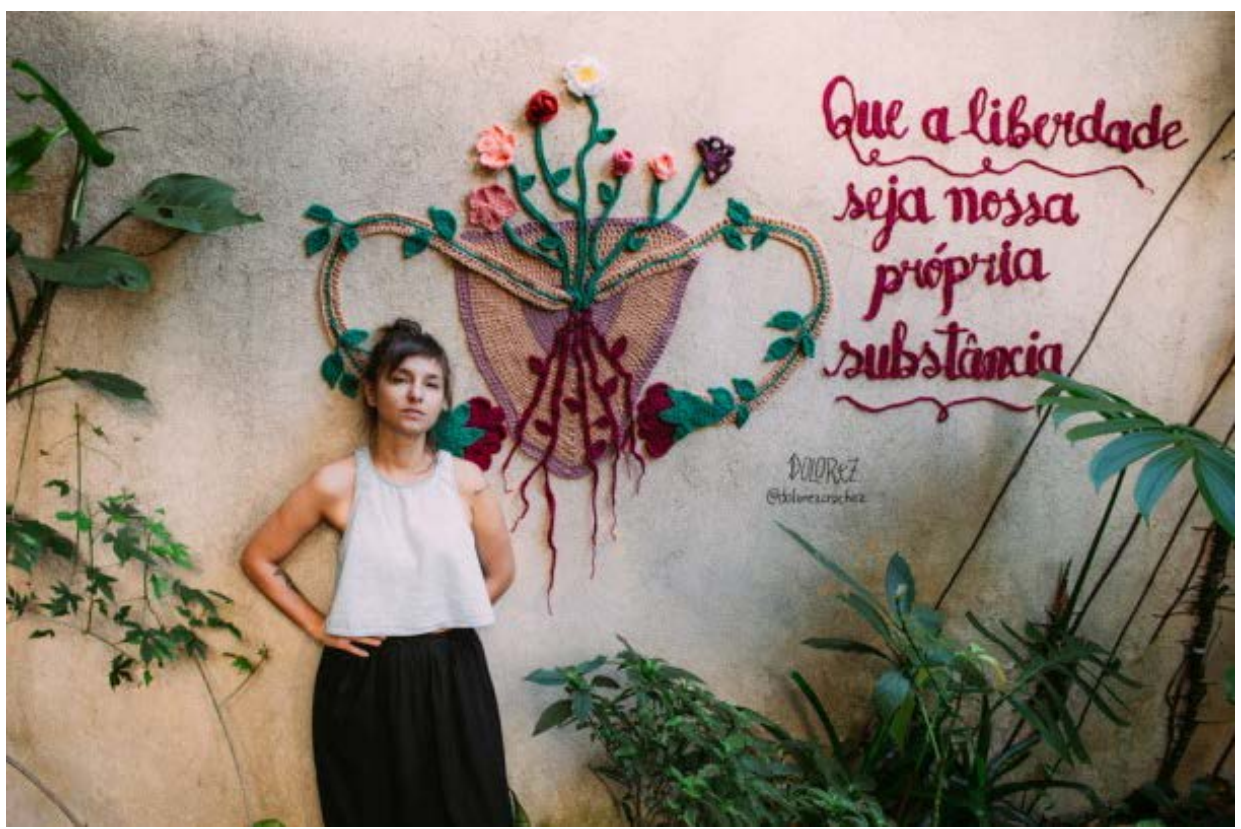

Imagen 6. Que la libertad sea nuestra propia sustancia. Dolorez Crochez.

Dolorez Crochez, teje sus grandes murales con materiales reciclados y posteriormente con pegamento, los adhiere a la pared. De la acción de tejer que la artista comenta haber vivido en su núcleo familiar, establece un diálogo de la historia de las mujeres con el arte contemporáneo y crea una nueva forma de expresión y de activismo feminista. Con sus intervenciones, además de querer embellecer la ciudad desde su particular mirada femenina, habla de temas como el aborto, el amor romántico y el medioambiente.

Uno de sus proyectos más críticos con los cánones de belleza que se imponen a las mujeres, es \#asflordapele. En él, contó con la colaboración de un fotógrafo, que retrató cuerpos de mujeres reales y sin retoques utilizando el cuerpo femenino sin erotizar, para denunciar los modelos de belleza irreales que se exigen por parte de las sociedades capitalistas. Posteriormente, Dolorez Crochez, decoró mediante su ganchillo las fotografías realizadas, que se colgaron por diferentes lugares de la ciudad. 


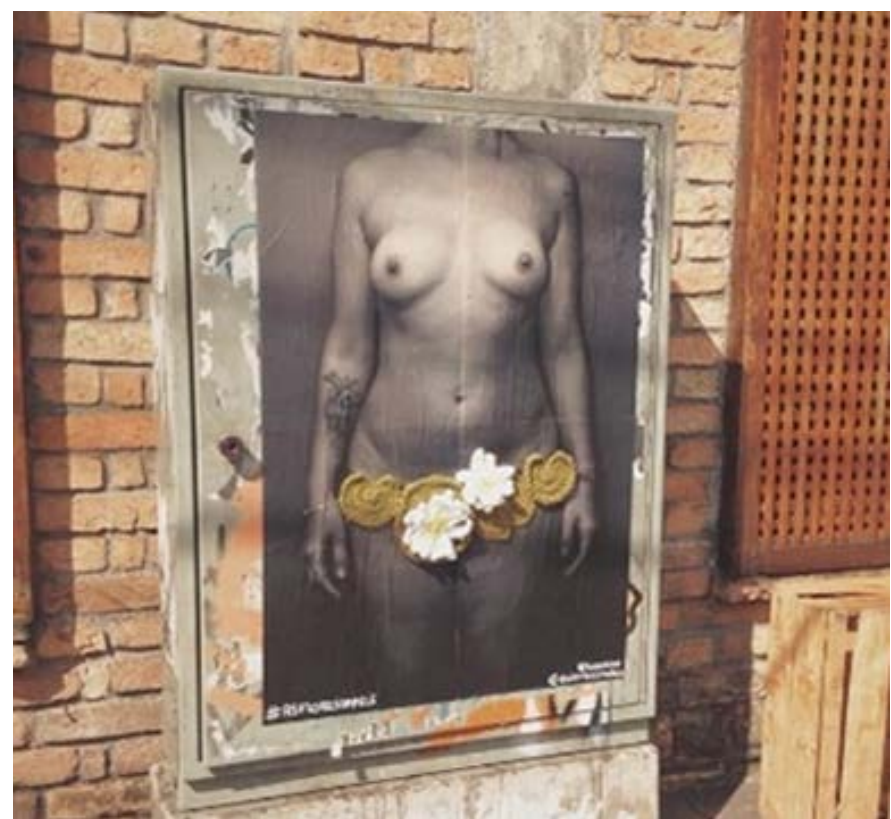

Imagen 7. \#asflordapele. Dolorez Crochez y Lucas Hirai.

Dando el salto ahora hasta Colombia, encontramos a Bastardilla. Esta artista de Bogotá utiliza la técnica del graffiti en la que se imponen los colores brillantes y vivos y su gran detallismo.

En su obra, frecuentemente nos presenta a mujeres fuertes que deben formar parte la de vida sociocultural y política del país, además de reivindicar sus raíces indígenas. La artista, mediante sus obras de gran formato, intenta recuperar los valores del cuidado y empatía tradicionalmente considerados femeninos, y volver a dotarlos de valor para las personas en relación con el entorno y su protección.

Además, sus graffitis conllevan una importante crítica al mundo globalizado y capitalista que actúa en detrimento del entorno natural y su conservación. Bastardilla recupera el binomio mujer/naturaleza y lo redefine, entendiendo que toda aquella ética de cuidados que siempre han llevado a cabo las mujeres y sobre la cual se ha sostenido el desarrollo de la vida pública de los hombres, es necesario volver a rescatarla y cuidar de nuestro entorno. 


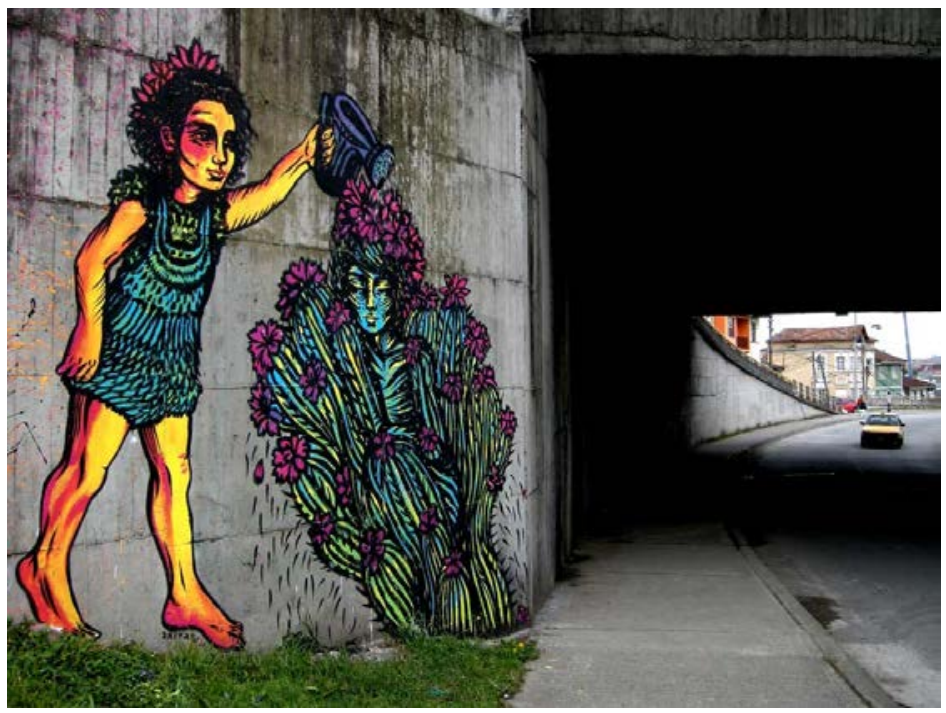

Imagen 8. Bastardilla S/T.

También en América Latina, concretamente en Bolivia, encontramos a Mujeres Creando. Poca presentación necesita este movimiento feminista, fundado en el año 1992 por María Galindo y Julieta Paredes como principales precursoras.

Mujeres Creando, nace como un movimiento feminista y pacifista con el objetivo principal de oponerse al mundo patriarcal que oprime a las mujeres. Su principal punto de acción, es oponerse a los restrictivos derechos reproductivos de las mujeres en Bolivia, principalmente por la despenalización del aborto.

Hoy en día, sigue siendo un delito la interrupción del embarazo penado con hasta tres años de cárcel, salvo excepciones contempladas en la ley como aquellos abortos practicados después de una violación, si existe riesgo para la salud de la mujer o si éstas son estudiantes con hijos o personas adultas o con discapacidad a su cargo.

Las acciones de Mujeres Creando tienen una particularidad especial que no comparten el resto de artistas que durante este artículo estamos conociendo. Su particularidad definitoria consiste en la colectividad de las acciones que realizan. Los graffiti, se hacen siempre desde la firma colectiva y nunca desde la individualidad. Esta característica supone un cambio en el paradigma a la hora de entender el graffiti: se pasa de unos orígenes de firma individual (el tag) como acto de transcendencia de la persona como individuo único a una firma 
colectiva que reclama derechos para todas las mujeres, en este caso (Pérez, 2017).

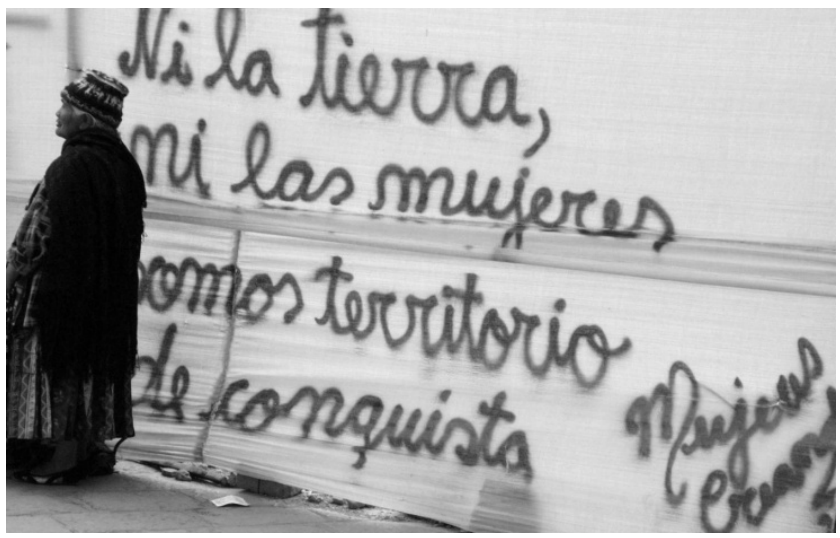

Imagen 9. Mujeres Creando. S/T

La estética de Mujeres Creando, sigue siempre los mismos estándares: una frase de protesta escrita en negro y con caligrafía podríamos decir que infantil, sobre un fondo blanco y acompañada de la firma colectiva.

Al igual que con Bastardilla, Mujeres Creando también denuncian la globalización de los países y su homogeneización así como la recuperación de valores de identidad con sus orígenes.

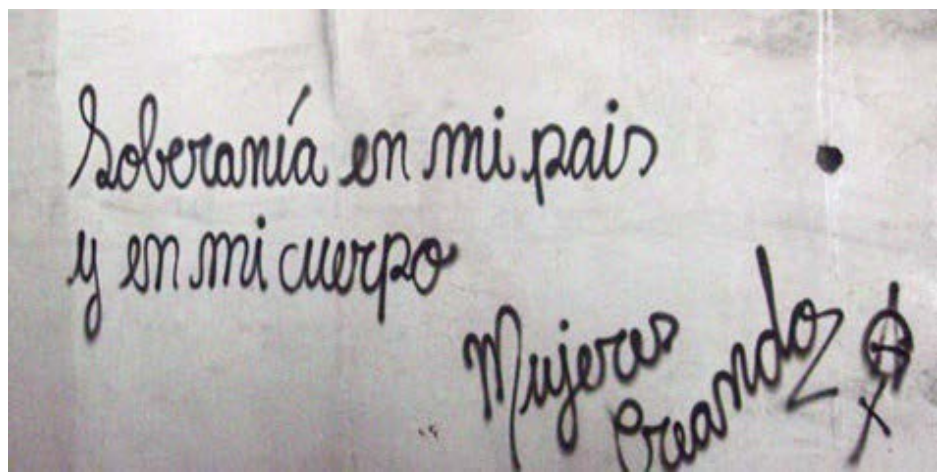

Imagen 10. Mujeres Creando. S/T

Adentrándonos ya en países de habla árabe, la abogada y escritora feminista Wassyla Tamzali, nos alerta sobre cómo la sexualidad de las mujeres en estos países, se ha utilizado como un método de represión basado en cuestiones religiosas (Tamzali, 2016). 
Además de esto, las mujeres árabes comienzan a tomar conciencia de su propia opresión cuando, después de haber sido las principales defensoras de los derechos civiles en las diferentes revueltas, entienden que han sido traicionadas a lo largo de la historia cuando se trataba de defender sus derechos por tratarse de asuntos aplazables.

Especial atención merecen los graffiti llevados a cabo por mujeres en estos países principalmente por el riesgo que asumen a la hora de realizarlos en el espacio público. Las artistas árabes no son especialmente llamativas por su innovación en técnicas pero sí lo son por las reflexiones y reivindicaciones que plantean además de por los grandes formatos que utilizan para sus obras.

Es el caso por ejemplo de Shamsia Hassani (1988), la primera mujer graffitera afgana. Hassani pinta a partir de los objetos y símbolos que la rodean por lo que siempre nos presenta a sus mujeres con el velo. Su principal objetivo es cambiar la sociedad y su modelo de pensamiento a través del arte queriendo que Afganistán sea famoso no por las guerras si no por su ambiente cultural y artístico.

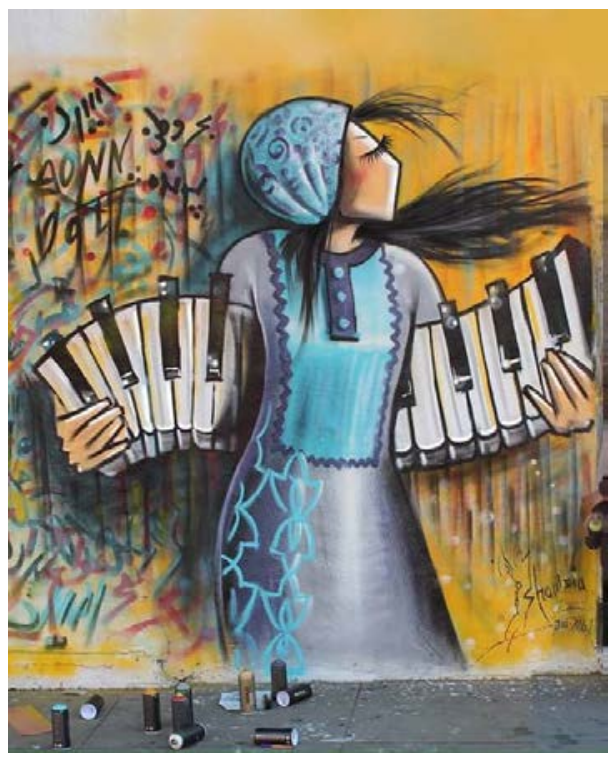

Imagen 11. Shamsia Hassani. S/T

Los velos, normalmente de color azul es el símbolo más representativo de esta artista que normalmente embellece lugares destruidos por las bombas con sus coloridos graffitis de mujeres fuertes y empoderadas. Las mujeres de Hassani, como ella misma explica vienen a mostrarnos una imagen alejada de estereotipos racistas, queriendo la artista pintar derechos con sus murales. En 
muchas de sus obras, las mujeres aparecen junto a instrumentos como símbolo de acceso a la cultura y la libertad.

Como hemos visto, gracias al arte urbano, las artistas pueden manifestar su voz y "hablar" de cualquier asunto que las preocupe o molesto y hacerlo desde la propia individualidad o no, para transmitir la voz colectiva de muchas mujeres. Los asuntos que preocupan a las mujeres son muchos y de muy diversos calados como hemos podido comprobar y entresacar de las diferentes pinturas mostradas: derecho al aborto, preocupaciones medioambientales, libertad económica y de expresión, urbanismo de género, envejecimiento activo, etc.

\section{UNA INTERVENCIÓN CON MUJERES A PARTIR DEL ARTE URBANO}

Recoge Ascensión Moreno (2016), un esquema establecido por Criado Pérez (2016) donde se establece qué aspectos se deberían de tener en cuenta a la hora de llevar a cabo un proyecto de mediación artística. Me gustaría recoger algunas de ellas que después ayudarán a clarificar algunas de las pretensiones que se perseguían con la intervención posterior:

- Espacio de seguridad, de experimentación: el taller es un espacio de juego, en el que se aprende haciendo y nadie interpreta nuestra obra.

- Expresión: se permite la expresión y la creación de las personas participantes bien de manera individual o grupal

- Proceso/ Resultado: Nos centramos en el proceso de la actividad y taller y valoramos el resultado. El tiempo es recomendable que sea amplio y continuado en el tiempo.

Todo lo que hemos venido recogiendo a lo largo de este artículo, es la base que permite después llevar a cabo una intervención práctica desde la óptica de la Educación Social, concretamente en un Aula de la Mujer. El taller que llevamos a cabo lleva por título "Arquicostura”.

\subsection{Aula de la Mujer}

La actividad propuesta, se dirige al Aula de la Mujer, gestionada por la Universidad Popular de Palencia e impartida en el CEAS Fernández Nieto, en el Barrio de San Antonio. El aula está a cargo de Concha Lobejón, maestra, educadora social y profesora de la UPP. 
El Aula de la Mujer, surge con el objetivo principal de dar respuesta a una necesidad de formación y capacitación a mujeres que bien en su infancia o juventud no la han recibido, además de ayudar a tejer redes entre las propias mujeres, de apoyo y ayuda entre iguales. En definitiva, empoderar a la mujer desde la formación integral (Pérez, 2017).

Las mujeres que participan, son mayores de 65 años y conformado por más o menos 24 participantes. En las sesiones regulares de las clases, una vez al mes llevan a cabo alguna actividad artística, lo cual esto me permite partir de la base de que las participantes tienen nociones artísticas.

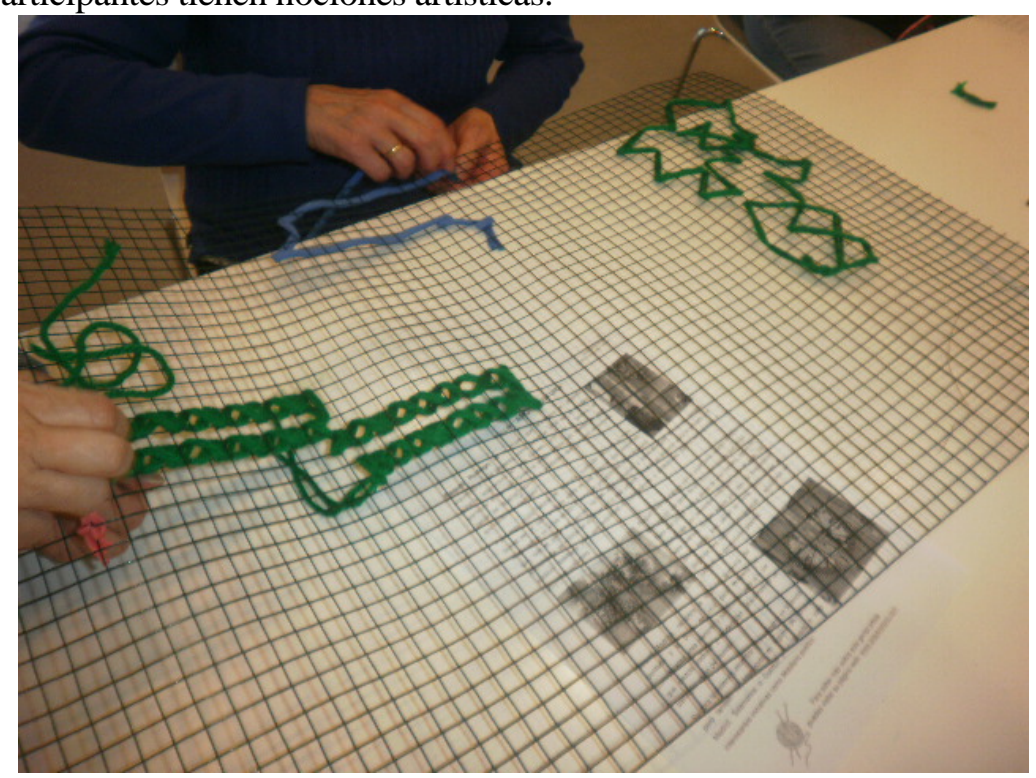

Imagen 12. Proceso, Actividad Arquicostura.

\subsection{Intervención}

El objetivo principal del taller, consiste en acercarnos a la obra de la artista valenciana Raquel Rodrigo y su proyecto Arquicostura elaborando diversos paneles tejidos. Para ello, se preparan para las alumnas diferentes patrones de los dibujos que se van a llevar a cabo: la palabra Igualdad, y diferentes flores. Estos dibujos, posteriormente se tejerán a unas rejillas de diferentes dimensiones: una de $0{ }^{\prime} 50 \mathrm{~cm}$ de alto por 2’5 m de largo, dos de 0’50 cm de alto por $1 \mathrm{~m}$ y una de 0 '50 cm de alto por 0’50 cm de largo.

Para tejer en la reja, utilizamos lanas y tela en trapillo, además de bridas para posteriormente sujetar la reja. 
La metodología se plantea participativa y colaborativa y partiendo de la base de que las alumnas ya conocen la obra de Arquicostura por una actividad anterior ${ }^{2}$ y otras publicaciones. ${ }^{3}$

Para llevar a cabo la actividad, se entregan diferentes patrones realizados previamente y que sirven de guía para después plasmarlo en la rejilla. Al inicio de la actividad, se establecen diferentes pautas sobre cómo llevarse a cabo la actividad para finalmente conseguir un panel al estilo de la artista Arquicostura.

Durante el desarrollo de la actividad surgieron diferentes complicaciones fuera de las previsiones tenidas en cuenta y su realización fue mucho más complicada de lo que se esperaba en el inicio de su preparación por diferentes cuestiones.

Era un trabajo muy ambicioso para las pocas alumnas que acudieron además de resultar dificultosa la realización de la tarea a la hora de tener que pasar las lanas y telas por la rejilla. Tras varios intentos con la plantilla entregada previamente, nos dimos cuenta de que no iba a poder realizarse como se había planeado.

Ante la frustración de las alumnas por no conseguir las pautas marcadas, decidimos dejar paso al estilo libre y que cada persona decidiese qué hacer y plasmar en la rejilla.

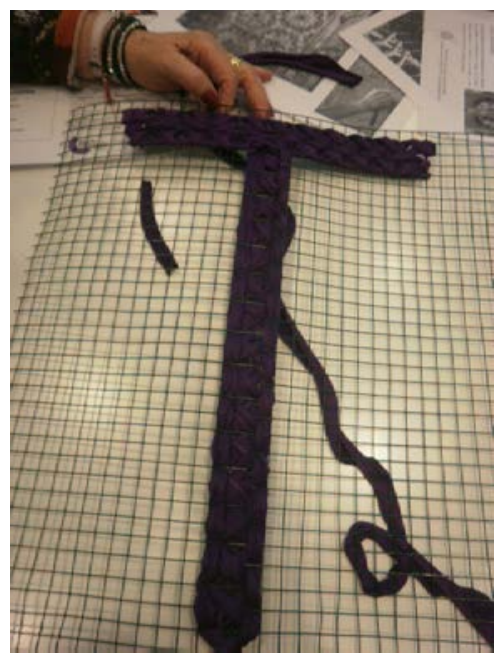

Imagen 13. Proceso, Actividad Arquicostura.

${ }^{2}$ En el Trabajo Fin de Grado Arte urbano, graffiti y activismo feminista. Un recurso para la Educación Social (2017) desarrollo la actividad a la que hago referencia.

3 Páginas. Boletín del área de educación. Universidad Popular de Palencia. № 74 
Como señalaba al inicio con las indicaciones de Ascensión Moreno, son varias las cuestiones que han de tenerse en cuenta a la hora de llevar a cabo un proyecto de características artísticas, independientemente del colectivo con el que se vaya a trabajar.

El tiempo de realización del que disponíamos fue escaso, por lo que para una ocasión futura puede ser recomendable utilizar al menos dos sesiones, dejando una de ellas para la iniciación y familiarización de los materiales con los que vamos a trabajar. Como señala Moreno (2016), la mediación artística despliega su máximo potencial cuando permite el desarrollo artístico de creaciones libres y personales, por lo que esta actividad, dado a sus características, nos permitió reconducirla hacia una creación libre y no tan pautada como se estableció en un primer momento. La misma autora señala la importancia del proceso y no tanto del resultado final de este tipo de actividades.

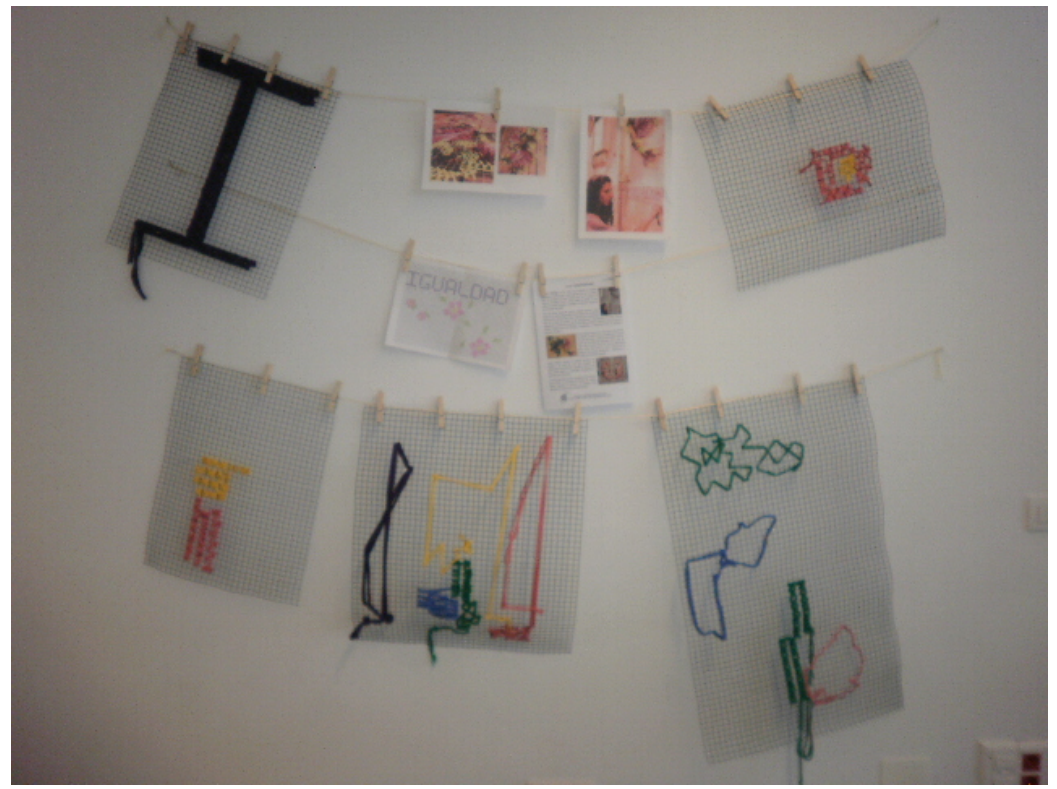

Imagen 14. Resultado final. Actividad Arquicostura.

\section{CONCLUSIONES}

Una vez vistas todas las posibilidades que el arte urbano y el graffiti tienen, es importante volver a destacar sus capacidades transformadoras para poder ser utilizados tanto en las intervenciones de los y las profesionales de la Educación Social, así como herramienta para el feminismo para continuar con las reivindicaciones todavía hoy vigentes. 
La labor de las mujeres dentro del arte urbano es destacable por dos motivos fundamentales: se adueñan del espacio público tantas veces negado y son pioneras en cuanto a técnicas y estilos. Además de esto, hemos visto como algunas de ellas vuelven a recuperara las técnicas menores y las ponen en valor recuperando con ello también la mirada femenina.

Destacable es también valorar la carga simbólica que conlleva que las mujeres tomen en muro para plantear en el espacio público "problemas de mujeres” y den en salto de la propia individualidad a la colectividad.

A lo largo de la historia, las mujeres artistas han contado con nulas referencias y ejemplos de artistas anteriores con las que poder identificarse. Esta explosión creativa por parte de mujeres de todo el mundo, considero que es una buena manera de tejer una genealogía feminista entre todas, donde prevalezcan valores como el respeto, la sororidad y la lucha colectiva.

Conocer todas las potencialidades que nos ofrece el arte, concretamente el urbano, puede convertirse en la mejor herramienta para intervenir en diferentes contextos y realidades. Durante este artículo nos hemos centrado en las posibilidades para las reivindicaciones feministas y la recuperación de nombres de mujeres artistas urbanas, pero gracias al graffiti y al muralismo, podremos trabajar con otros grupos vulnerables o en situación de exclusión, objeto de intervención para la Educación Social: infancia, juventud, exclusión, discapacidad, pobreza, etc.

Desde la creación artística, se permite diferentes espacios de reflexión para favorecer cambios sociales, políticos y culturales desde las propias comunidades.

\section{BIBLIOGRAFÍA}

De Blas, A. (2018). Gráfica feminista: En el muro de la memoria. Nueva Revolución. Periodismo alternativo. Recuperado en enero de: https://nuevarevolucion.es/grafica-feminista-muro-la-memoria/

De Diego, E. (2001). Al final sí había mujeres artistas. Babelia, El País. Recuperado en febrero de: https://elpais.com/diario/2001/11/03/babelia/1004745970_850215.html 
De Diego, J. (2000). Graffiti. La palabra y la imagen. Barcelo, España: Los libros de la Frontera.

Ganz, N. (2006). Arte urbano en los cinco continentes. Barcelona, España: Gustavo Gili.

Karen Dolorez transforma croché em arte urbana e espalha mensagens inspiradoras sobre o universo feminino. (2017). Follow the colours. Recuperado en marzo de 2018 de: http://followthecolours.com.br/art-attack/karen-dolorez-artecroche/

Martínez López, G. (2016). Wassyla Tamzali “El feminismo no habla de moral, habla de libertad". Diagonal Periódico. Recuperado en abril de 2018 de: https://www.diagonalperiodico.net/global/30482-feminismo-no-hablamoral-habla-libertad.html

Millet, K. (1970). Sexual politics. Garden City, New York: Doubleday.

Moreno, A. (2016). La mediación artística. Arte para la transformación social, la inclusión social y el desarrollo comunitario. Barcelona: Octaedro.

Pérez, T. (2017). Arte urbano, graffiti y activismo feminista. Un recurso para la educación social. (Trabajo Fin de Grado). Universidad de Valladolid, Palencia. http://uvadoc.uva.es/handle/10324/28477

Pérez, T. (2017-2018). Arte urbano y graffiti hecho por mujeres. Páginas. Boletín del área de educación. Universidad Popular de Palencia, (74). 